\title{
RESEARCH
}

Open Access

\section{Psychometric validation of a Saudi Arabian version of the sf-36v2 health survey and norm data for Saudi Arabia}

\author{
Ahmad AboAbat ${ }^{1}$, Hazem Qannam², Jakob Bue Bjorner ${ }^{3}$ and Mohamad Al-Tannir ${ }^{4 *}$
}

\begin{abstract}
Background: Adaptation of a patient-reported outcomes survey into a new language requires careful translation procedures as well as qualitative and quantitative psychometric testing. This study aimed to evaluate the basic psychometric properties of the new Saudi Arabian SF-36V2 and establish norm data for Saudi Arabia.
\end{abstract}

Methods: Translation and adaptation of the SF-36v2 used standard methodology. Psychometric validation included two stages: 1) A qualitative study $(n=100)$ explored the components of health and health-related quality of life considered important in Saudi Arabia and evaluated the content validity of the SF-36v2 in Saudi Arabia, and 2) A quantitative study ( $n=6166$ ) evaluated the basic psychometric properties of the Saudi SF-36V2 and established norm data for Saudi Arabia. Comparison with US general population data $(n=4040)$ evaluated differential item function (DIF) and cross-national differences.

Results: The qualitative study supported the content validity of the Saudi SF-36v2. Cognitive debriefing identified only few and minor problems. Psychometric analyses supported item convergence within scales and differentiation across scales of the SF-36v2. Scale level exploratory factor analyses did not support the typical distinction between physical health and mental health components. Internal consistency reliability was satisfactory for all scales except the social function scale (alpha $=0.67)$. Cross-national DIF was identified for 9 items. In the Saudi general population, the average vitality score was lower for women ( -2.71 points) compared to men. For men, older age groups scored lower on the physical function scale $(-3.31)$ and the physical health component $(-3.06)$. For women, older age groups scored lower on the role physical $(-3.72)$, bodily pain $(-3.66)$, and vitality $(-2.32)$ scales as well as the physical health component (-3.52). Compared to the 2009 United States general population, and after adjusting for age, gender, and differential item function, persons in Saudi Arabia had lower average scores for the physical function $(-3.10)$, role physical $(-4.75)$, social function $(-4.23)$, role emotional $(-5.67)$, and mental health $(-4.82)$ scales, as well as the mental health component $(-4.57)$.

Conclusion: This Saudi normative study of patient reported outcomes supported the validity and reliability of the new Saudi SF-36v2 and found cross-national differences with the USA.

Keywords: Quality of life, Norms, SF-36v2, Validity, Population-based survey, Saudi Arabia

\footnotetext{
* Correspondence: maltannir@kfmc.med.sa

${ }^{4}$ Research Center, King Fahad Medical City, PO Box 59046, Riyadh 11525,

Kingdom of Saudi Arabia

Full list of author information is available at the end of the article
}

\section{Springer Open}

(c) The Author(s). 2020 Open Access This article is licensed under a Creative Commons Attribution 4.0 International License, which permits use, sharing, adaptation, distribution and reproduction in any medium or format, as long as you give appropriate credit to the original author(s) and the source, provide a link to the Creative Commons licence, and indicate if changes were made. The images or other third party material in this article are included in the article's Creative Commons licence, unless indicated otherwise in a credit line to the material. If material is not included in the article's Creative Commons licence and your intended use is not permitted by statutory regulation or exceeds the permitted use, you will need to obtain permission directly from the copyright holder. To view a copy of this licence, visit http://creativecommons.org/licenses/by/4.0/. 


\section{Background}

Patients' self-reports of health outcomes are important for measuring the impact of chronic disease, accounting for changes in health, measuring the effects of treatment, and predicting health resource utilization and thus medical expenditures. To date, most of the available patientreported outcome (PRO) measures are in English, and few have been translated into Arabic and adapted for use in Arab countries [1]. Because the perception of health-related outcomes may differ between populations and conditions, adaptation of a questionnaire into a new language and culture requires more than just a translation. Evaluation of content validity, construct validity, and reliability as well as establishing national normative data are important steps in the translation and cultural adaptation of a PRO measure [2-9]. Despite these challenges, the literature urges investigators not to "reinvent the wheel" by developing new or ad hoc measures, but rather cross-culturally adapt an existing health and health-related quality of life (HRQOL) measure. Crosscultural adaptation is believed to: 1 ) be more costeffective; 2) enable efficient utilization of the existing body of knowledge; 3) help standardize the concept internationally; and 4) offer the opportunity for international comparative studies. A disadvantage of culturespecific instruments is that their results are not generalizable or comparable because each has its conceptual definition and choice of indicators [6].

The SF-36 is one of the most widely used PRO instruments [10]. Its validity, reliability, and responsiveness have been documented in many groups varying by age, sex, socio-economic status, geographical region, and clinical conditions [3]. In the 1990s, researchers within the well-documented International Quality of Life Assessment (IQOLA) project pioneered the adaptation of the SF-36 for use internationally [11]. The methods used in the IQOLA project, still constitute the standard for translation and validation work today. The SF-36 has been translated into more than 150 languages and adapted to different cultures [10]. Responding to the difficulties in translating various items and response choices, the IQOLA project's investigators emphasized the importance of developing translations that are culturally appropriate to each country [2].

Published norms for the SF-36 exist in several developed countries [4,11-21]. Norms permit evaluation of disease burden, i.e. the decrement in PRO scores relative to a general population comparison group with similar age and sex distribution [10]. Normative data can also help interpretation of treatment effects since no treatment effect can be expected to be larger than the disease burden. For Saudi Arabia, PRO population norms could help identify needs and subsequently guide health policies, legislation, and the development of strategic plans to allocate resources based on unmet needs. However, most previous work in Saudi Arabia has used the SF36v1 or RAND-36 [22], rather than SF-36v2, and general population norms have been lacking.

Accordingly, this nationwide study aimed to explore the content validity of SF-36v2 in a Saudi Arabian context, test the validity and reliability of a new Saudi Arabic SF-36v2 translation, and collect Saudi normative SF-36v2 data. Since the SF-36v2 scoring is based on US general population norms, we also explored the difference between US and Saudi Arabian norms.

\section{Methods}

This project was performed in 2 stages, utilizing both qualitative and quantitative methods.

The qualitative study had two objectives: 1) To explore the concepts of health and HRQOL and evaluate the content validity of the SF-36v2 as an HRQOL instrument in a Saudi Arabic setting, and 2) To perform cognitive debriefing of the Saudi SF-36v2.

Semi-structured interviews were carried out on a convenience sample of 100 participants by trained interviewers aiming to explore which domains the participants consider important components of health and HRQOL, and to ascertain concordance with the WHO definition of health as "a state of complete physical, mental, and social well-being and not merely the absence of disease or infirmity" [23]. This definition forms the conceptual basis of the SF-36 and other commonly used HRQOL measures. Participants were asked introductory questions including: "What is the meaning of health?", "What do you think may affect a person's health?", and "What areas of life do you think are affected by health?" Participants were probed to elaborate on their answers until they indicated having no more ideas. Participants were then asked to evaluate the importance of domains commonly used in measuring HRQOL using a four-point scale ("very important", "quite important", "not quite important", and "not at all important"). Next, participants were asked to list additional domains that were not mentioned among the listed domains. It has been suggested that indicators could be added if rated important by at least $50 \%$ of subjects [24].

Subsequently, participants engaged in a cognitive debriefing of the Saudi SF-36v2 to evaluate whether the content of the translated version was easily understood and culturally relevant within a Saudi Arabian context. After completing each item, participants were asked questions about clarity, comprehensibility, relevance, and completion feasibility using a standardized response scale. The participants were probed to elaborate on their answer, using probes such as: "Interesting, can you elaborate on that?", "What do mean, can you explain 
further?", "How important is that to you?", "Do you want to add anything in this regard?"

The quantitative study was based on a national general population survey involving Saudis aged 15 years or older. Saudi Arabia is divided into five regions (North, South, Central, East, and West); each region is divided into sub-regions and blocks. A probability proportional sampling method was used to randomly select subregions, blocks, and accordingly households. Households were chosen from each block and a roster of household members (based on age and sex) was collected by a surveyor visiting the household. An adult aged 15 years or older was randomly selected to be surveyed from each household. The surveyor handed out the SF-36v2 for self-administration. Individuals were excluded if they were unable to complete the questionnaire due to language problems, communication limitations or cognitive impairments. If the selected adult was not present, our surveyors made an appointment to return. The household was counted as nonresponsive after a total of three attempted unsuccessful visits.

The Saudi population is estimated to be approximately $12,167,245$ people. The study aimed to obtain 6360 completed surveys. This sample was chosen to achieve sufficient representation of all strata of the Saudi population. Based on experience with surveys in Saudi Arabia, we assumed a non-response rate of up to $40 \%$ for a target of 10,600 contacts. Of the 10,592 approached Saudi adults, 6166 participated in the study with a response rate of $61 \%$.

The Saudi Arabian data was compared to United States (US) general population data $(n=4040)$ obtained in 2009 [25]. This general population online survey of US citizens 18 years or older has been used to generate population norms for the USA (please see [25] for details).

\section{Measures}

SF-36v2 was administered using a new Arabic version and scored according to standard recommendations of the SF-36v2 developers [25] into eight subscales: physical function (PF), role limitations due to physical health $(\mathrm{RP})$, bodily pain (BP), general health perception $(\mathrm{GH})$, vitality (VT), social function (SF), role limitations due to emotional problems (RE), and mental health $(\mathrm{MH})$. For each subscale: 1) items were coded so that high score indicated good health, 2) two items were weighted [26], for all other items simple category weights $(1,2,3 \ldots)$ were used, 3) the mean score was taken across items and transformed linearly to a metric from 0 to 100,4 ) for norm based scoring, the scale score was transformed linearly so that the US general population has a mean of 50 and an SD of 10. Also, two overall component scores, the physical component summary (PCS) and the mental component summary (MCS) were calculated based on scoring coefficients from a principal component analysis with orthogonal rotation [27].

The translation of the SF-36v2 used the principles of good practice from the International Society of Pharmacoeconomics and Outcomes Research Task Force for Translation and Cultural Adaptation [28]. This included: 1) Forward translation by two independent professional translators, 2) Back translation by a third independent translator, 3) Reconciliation by an expert panel, and 4) Independent assessment of translation quality. The translation was subsequently evaluated by cognitive debriefing and quantitative testing, as reported in this paper.

Morbidity questions included a list of 27 self-reported health conditions (hypertension, heart disease, diabetes, arthritis, depression, etc.) and one open-ended response coded as "other".

Sociodemographic questions included age, gender, education level, marital status, occupation, and financial status (monthly household income). Additional questions concerned smoking habits and major life events during the previous year.

\section{Statistical analysis}

Distributions of basic demographic variables and chronic conditions were described through standard frequency tables. The analysis of scale structure relied on multitrait analyses [29], which have been used in multiple previous studies of the SF-36. These analyses test item convergence within scales and item differentiation across scales. Item convergence within scales (sometimes called convergent validity) was evaluated by analyzing the correlation of each item with the sum of all the other items in the scale (item-own-scale correlation has been corrected for overlap, also see [30]). A correlation of 0.40 or more for all items in a scale supports item convergence within scales. Item differentiation across scales (sometimes called discriminant validity) was evaluated for each item by comparing the item's correlation with its scale to its correlation with all other scales. Item differentiation across scales is supported if the item's correlation with its own scale is significantly larger than its correlation with any other scale. Furthermore, we analyzed the scale correlation matrix using exploratory factor analysis as in many previous studies of the SF-36 (e.g. [31, 32]). Number of factors were evaluated by Eigen value analysis. Factors were extracted using the principal components method, followed by orthogonal rotation (Varimax). While most studies have used a two-factor solution of physical and mental health [31], analyses in some non-Western countries have suggested a threefactor structure of physical, mental, and social health [32]. For this reason, we evaluated both two- and three- 
factor solutions. As robustness analyses, we supplemented the Varimax rotation with an oblique rotation (Promax) and supplemented standard analyses of product-moment correlations with analyses of the polychoric correlation matrix.. Internal consistency reliability (coefficient alpha) was estimated for the subscales. Internal consistency reliability for the PCS and MCS was estimated using methods for weighted composites (see [33] page 37).

Differential item function (DIF) was evaluated for age, gender, and comparisons of Saudi Arabia and USA using logistic regression DIF tests [34]. Adopting a standard decision rule [35], evaluation of important DIF was based on statistical significance ( $p<0.05$ after Bonferroni adjustment) and magnitude in terms of increase in explained item variance (difference in pseudo R-squared [36] larger than 0.03). This criterion is slightly less conservative than a threshold of 0.035 advocated in the educational testing literature [37]. We used a standard purification strategy [34], where items with indications of DIF were excluded iteratively until a set of anchor items without DIF was identified. Then, the final DIF analyses were conducted for each item using the anchor items and the item in question. In cases of important cross-national DIF, we adjusted the cross-national comparisons using the generalized partial credit item response theory (IRT) model [38]. This model can adjust for uniform DIF (DIF with the same magnitude across score levels) by adjustment of the IRT thresholds parameters and adjust for non-uniform DIF (magnitude of DIF depends on score level) by adjustment of the IRT discrimination parameter. DIF adjustment was performed using a three step procedure: 1 ) We estimated item parameters for all SF-36v2 scales using the US data and the generalized partial credit IRT model [38], 2) For items with significant DIF, we re-estimated the item parameters in the Saudi data, fixing item parameters for the anchor (no-DIF) items, and 3) We performed IRTbased sum score cross-calibration to link the Saudi scale scores to the US metric [39]. After doing this for all subscales with DIF, we calculated adjusted PCS and MCS scores based on the adjusted subscales.

Comparisons between Saudi Arabia and the USA were carried out using a linear regression model, with and without controlling for differences in age and gender, and adjustment for DIF. The magnitude of differences was evaluated according to published guidelines for minimal important differences (MID) for the SF-36v2 [25]: PF: 3 points, RP: 3 points, BP: 3 points, GH: 2 points, VT: 2 points, SF: 3 points, RE: 4 points, MH: 3 points, PCS: 2 points, and MCS: 3 points. These MID values have been established using anchors such as noticeable increase in risk of mortality, job loss, or hospitalization [40].

\section{Results}

Health and HRQOL concepts

The characteristics of the sample $(N=100)$ used in the qualitative study are presented in Table 1.

In the qualitative study, four concepts were endorsed by $50 \%$ or more of participants as components of health: physical functioning (70\% of participants), normal psychological function and feelings (66\%), healthy eating habits and enjoyment of food (61\%), normal social functioning (50\%); $38 \%$ of participants defined absence of disease or illness and $28 \%$ being full of energy (free from pain and fatigue) as components of health (Table 2).

When presented with a list of domains commonly including in the assessment of HRQOL, concepts related to all eight SF-36 domains were assessed as "quite" or "very" important for HRQOL (Range 95\% - 100\%, Table 3). While the concept of being full of energy was considered as a component of health by only $28 \%$ of the sample, related concepts of "having a lot of energy" and "being free from pain" was considered a "very" or "quite" important components of HRQOL by $100 \%$ and $96 \%$ of participants, respectively. Participants also reported some additional domains that are not covered by the SF36 as important: eating habits (72\%), sleep (55\%), travel (53\%), and sexual function (56\%) (Table 3).

We identified four SF-36v2 items that two or three participants (out of 100) had problems understanding: HT (Health compared to 1 year ago), RP4 (Difficulty performing work due to physical health), VT4 (Feeling tired),

Table 1 Socio-demographic Characteristics of Participants in the Qualitative Study $(n=100)$

\begin{tabular}{|c|c|c|}
\hline \multirow[t]{3}{*}{ Age (in years) } & Median & 30 \\
\hline & STD & 14 \\
\hline & Age range & $15-70$ \\
\hline \multirow[t]{2}{*}{ Gender } & Male & $79 \%$ \\
\hline & Female & $21 \%$ \\
\hline \multirow[t]{3}{*}{ Marital Status } & Married & $51 \%$ \\
\hline & Widowed/divorced & $3 \%$ \\
\hline & Single & $47 \%$ \\
\hline \multirow[t]{6}{*}{ Employment Status } & Full-time student & $11 \%$ \\
\hline & Part-time student & $2 \%$ \\
\hline & Working full-time & $72 \%$ \\
\hline & Working part-time & $5 \%$ \\
\hline & Retired & $9 \%$ \\
\hline & Homemaker & $1 \%$ \\
\hline \multirow[t]{5}{*}{ Education Level } & Less than high school & $19 \%$ \\
\hline & High school & $24 \%$ \\
\hline & Some College & $10 \%$ \\
\hline & College/University & $39 \%$ \\
\hline & Postgraduate & $8 \%$ \\
\hline
\end{tabular}


Table 2 Conceptual Domains Considered Components of Health

\begin{tabular}{ll}
\hline & \\
\hline Normal physical functioning (including general mobility, exercises, and sports) & $70 \%$ \\
Normal psychological function and feelings (happiness, love, peace, and stress-free) & $66 \%$ \\
Eating (healthy habits, enjoyment of food) & $61 \%$ \\
Normal social functioning (with family and friends) & $50 \%$ \\
Good sleep (habits, duration, quality, and uninterrupted) & $49 \%$ \\
Normal daily activities (self-care, housework, work, schooling, etc.) & $49 \%$ \\
Free from illness & $38 \%$ \\
Full of energy (free from pain or fatigue) & $28 \%$ \\
Performing religious acts (going to the mosque) & $25 \%$ \\
Leisure functions (primarily travel and outings) & $17 \%$ \\
Normal cognitive function & $8 \%$ \\
Others (good finance, health checkup, normal weight, etc.) & $7 \%$ \\
\hline
\end{tabular}

and GH3 (Healthy as anybody). No other problems were identified for any other item at this stage.

\section{Quantitative sample characteristics}

Compared with the 2009 USA general population, the Saudi sample was younger (49.4\% in the age range $15-29$ years, with $47.3 \%$ in the age range $18-29$ years vs. $22.0 \%$ in the USA), included a higher proportion of never married (43.8\% vs. $26.9 \%$ ), and a lower proportion of divorced/separated $(3.1 \%$ vs. $15.6 \%)$. More people in the Saudi sample had received a college degree $(43.2 \%$ vs. $35.0 \%)$ (Table 4$)$. Differences in reporting of employment status precluded a detailed comparison, but $48.6 \%$ of the Saudi sample was working compared to $53.3 \%$ in the USA sample.

Table 3 Importance Ratings of Health Related Quality of Life Domains

\begin{tabular}{|c|c|c|c|c|c|}
\hline Domain & Not at all Important & Not Quite Important & Quite Important & Very Important & $\begin{array}{l}\text { Important } \\
\text { Total }\end{array}$ \\
\hline Function (i.e. what a person is able to do) & $0 \%$ & $0 \%$ & $5 \%$ & $94 \%$ & $99 \%$ \\
\hline Having a lot of energy & $0 \%$ & $0 \%$ & $11 \%$ & $89 \%$ & $100 \%$ \\
\hline Ability to carry out daily activities & $3 \%$ & $0 \%$ & $14 \%$ & $83 \%$ & $97 \%$ \\
\hline Feelings and emotions & $0 \%$ & $0 \%$ & $17 \%$ & $83 \%$ & $100 \%$ \\
\hline Physically functioning & $1 \%$ & $0 \%$ & $17 \%$ & $82 \%$ & $99 \%$ \\
\hline Being free from pain & $4 \%$ & $0 \%$ & $23 \%$ & $73 \%$ & $96 \%$ \\
\hline Being a happy person & $1 \%$ & $0 \%$ & $26 \%$ & $73 \%$ & $99 \%$ \\
\hline Change in health & $3 \%$ & $0 \%$ & $29 \%$ & $68 \%$ & $97 \%$ \\
\hline Not feeling tired & $5 \%$ & $0 \%$ & $33 \%$ & $62 \%$ & $95 \%$ \\
\hline Social functioning & $2 \%$ & $0 \%$ & $42 \%$ & $56 \%$ & $98 \%$ \\
\hline Subjective health perception & $2 \%$ & $0 \%$ & $45 \%$ & $53 \%$ & $98 \%$ \\
\hline \multirow[t]{8}{*}{ Additional Reported Domains ${ }^{a}$} & \multicolumn{4}{|c|}{ Eating (habits and enjoyment) } & $72 \%$ \\
\hline & \multicolumn{4}{|l|}{ Sexual function } & $56 \%$ \\
\hline & \multicolumn{4}{|l|}{ Sleep } & $55 \%$ \\
\hline & \multicolumn{4}{|c|}{ Travel (for pleasure and religious) } & $53 \%$ \\
\hline & \multicolumn{4}{|c|}{ Environment (housing, hygiene, pollution) } & $39 \%$ \\
\hline & \multicolumn{4}{|l|}{ Finance } & $25 \%$ \\
\hline & \multicolumn{4}{|c|}{ Religion (relationship with God/spirituality/personal/life attitude) } & $22 \%$ \\
\hline & \multicolumn{4}{|c|}{$\begin{array}{l}\text { Others: health status, the presence and quality of health services, relaxations and free time, } \\
\text { success at work }\end{array}$} & $19 \%$ \\
\hline
\end{tabular}

apatient were asked "Apart from the domains mentioned above, please list all other HRQOL domains that you think are important." results reported here as frequency of reporting of additional domains 
Table 4 Socio-demographic Characteristics of the Participants in the Quantiative Study

\begin{tabular}{|c|c|c|c|c|}
\hline & \multicolumn{2}{|c|}{ Saudi Arabia } & \multicolumn{2}{|l|}{ USA } \\
\hline & Count & $\%$ & Count & $\%$ \\
\hline \multicolumn{5}{|l|}{ Age group } \\
\hline $15-29$ years $^{\mathrm{a}}$ & 2962 & 49.4 & 887 & 22.0 \\
\hline 30-44 years & 1695 & 28.3 & 1089 & 27.0 \\
\hline $45-59$ years & 952 & 15.9 & 1151 & 28.5 \\
\hline $60+$ years & 392 & 6.5 & 909 & 22.5 \\
\hline Missing & 165 & & 0 & \\
\hline \multicolumn{5}{|l|}{ Gender } \\
\hline Male & 2903 & 47.5 & 1940 & 48.1 \\
\hline Female & 3209 & 52.5 & 2096 & 51.9 \\
\hline Missing & 54 & & 0 & \\
\hline \multicolumn{5}{|l|}{ Marital status } \\
\hline Married & 3111 & 51.0 & 2081 & 51.6 \\
\hline Widowed & 130 & 2.1 & 239 & 5.9 \\
\hline Divorced/separated & 187 & 3.1 & 630 & 15.6 \\
\hline Single/Never married & 2671 & 43.8 & 1086 & 26.9 \\
\hline Missing & 67 & & 0 & \\
\hline \multicolumn{5}{|l|}{ Education } \\
\hline At most high school & 2575 & 42.8 & 1777 & 44.0 \\
\hline Some college or similar & 840 & 14.0 & 847 & 21.0 \\
\hline College degree & 2602 & 43.2 & 1412 & 35.0 \\
\hline \multicolumn{5}{|l|}{ Region } \\
\hline Central & 2392 & 38.9 & & \\
\hline Eastern & 783 & 12.7 & & \\
\hline Western & 2330 & 37.9 & & \\
\hline Northern & 126 & 2.1 & & \\
\hline Southern & 513 & 8.4 & & \\
\hline Missing & 22 & & & \\
\hline
\end{tabular}

aUS sample 18-29

Data on self-reported health conditions (Table 5) also showed noticeable differences between Saudi Arabia and the USA. In Saudi Arabia, the most prevalent conditions were: trouble seeing (26.1\%), back problems (18.0\%), anemia (15.8\%), and allergies (15.3\%). Trouble seeing was much less frequently reported in the USA (12.1\%), but several other conditions were considerably more prevalent in the USA: allergies (47.9\%), hypertension (32\%), arthritis $(26.4 \%)$, anxiety (17.2\%), and depression (14.1\%).

Item convergence within scales, item differentiation across scales

Table 6 presents results of analyses of item convergence within scales and differentiation across scales in the Saudi sample. The numbers in bold show each item's correlation with the sum of all the other items in its own scale (item-own-scale correlations). All items satisfied the standard criterion of item convergence within scales $(\geq 0.40)$. For all items except one, the item-ownscale correlation was higher than the correlation with any other scale, thus supporting item differentiation across scales. One item, SF01 ("During the past 4 weeks, to what extent has your physical health or emotional problems interfered with your normal social activities with family, friends, neighbors, or groups?"), showed a higher correlation with the pain scale than with the other item in its own scale.

\section{Exploratory factor analysis and internal consistency reliability}

While all scales were positively correlated, no correlations between scales were strong (above 0.70) supporting the notion that the eight scales measure distinct domains 
Table 5 Self-reported Health Conditions among Respondents in Saudi Arabia and the USA

\begin{tabular}{|c|c|c|c|c|}
\hline & $\begin{array}{l}\text { Saudi } A \\
(n=608\end{array}$ & & $\begin{array}{l}\text { USA } \\
(n=440\end{array}$ & \\
\hline & Count & Percentage & Count & Percentage \\
\hline Trouble seeing & 1591 & 26.1 & 533 & 12.1 \\
\hline Back problems & 1098 & 18.0 & 948 & 21.6 \\
\hline Anemia & 960 & 15.8 & 475 & 10.8 \\
\hline Allergies (chronic or seasonal) & 932 & 15.3 & 2105 & 47.9 \\
\hline Obesity & 678 & 11.1 & 782 & 17.8 \\
\hline Sleep disorders, insomnia, sleep apnea & 668 & 11.0 & 438 & 10.0 \\
\hline Hypertension & 624 & 10.2 & 1410 & 32.0 \\
\hline Migraine/Severe headaches & 614 & 10.1 & 838 & 19.0 \\
\hline Irritable Bowel Syndrome & 571 & 9.4 & 352 & 8.0 \\
\hline Ulcer or stomach disease & 536 & 8.8 & 242 & 5.5 \\
\hline Diabetes & 523 & 8.6 & 548 & 12.5 \\
\hline Asthma & 447 & 7.3 & 415 & 9.4 \\
\hline Chronic fatigue & 389 & 6.4 & 180 & 4.1 \\
\hline Gastro esophageal reflux disease & 373 & 6.1 & 632 & 14.4 \\
\hline Skin conditions & 312 & 5.1 & 406 & 9.2 \\
\hline Heart disease & 303 & 5.0 & 527 & 12.0 \\
\hline Arthritis or chronic joint problems & 297 & 4.9 & 1161 & 26.4 \\
\hline Emphysema, chronic bronchitis, COPD & 247 & 4.1 & 258 & 5.9 \\
\hline Trouble hearing & 181 & 3.0 & 432 & 9.8 \\
\hline Kidney disease & 173 & 2.8 & 92 & 2.1 \\
\hline Cancer & 119 & 2.0 & 239 & 5.4 \\
\hline Anxiety (clinical) & 116 & 1.9 & 758 & 17.2 \\
\hline Depression (clinical) & 111 & 1.8 & 620 & 14.1 \\
\hline Stroke & 95 & 1.6 & 117 & 2.7 \\
\hline Liver disease & 53 & 0.9 & 112 & 2.6 \\
\hline Limited Use of arm(s) or leg(s) & 53 & 0.9 & 397 & 9.0 \\
\hline
\end{tabular}

(data not shown). The highest scale correlation (0.67) was seen between RP and RE. In exploratory factor analysis, the first four Eigen values were: 4.07, 1.08, 0.78, 0.57, thus supporting a two-factor solution. In a two-factor model, the factor loadings did not concur with the hypothesized associations (Table 7). Rather, the PF, RP, and RE subscales loaded strongly on first factor (Physical and role function), while the $\mathrm{BP}, \mathrm{GH}, \mathrm{VT}, \mathrm{SF}$, and $\mathrm{MH}$ subscales loaded strongly on the second factor (Symptoms, health perception and social function). Analyses using oblique rotation and analyses of polychoric correlations provided similar results (data not shown). A three factor solution kept the first factor unchanged, but split the second factor into a factor on Symptoms and general health perception (BP, GH, and VT loaded strongly on this factor) and a factor on Social function and mental health (SF and $\mathrm{MH}$ loaded strongly on this factor, which also had a strong cross-loading from RE, data not shown).

Internal consistency reliability was above the traditional threshold of 0.70 for seven scales. The two-item SF scale had a reliability of 0.67 . The internal consistency reliabilities were 0.91 for PCS and 0.90 for MCS.

\section{Differential item function}

We did not identify any DIF with regards to age and sex. Uniform and non-uniform cross-national DIF was identified for 4 and 5 items, respectively, based on explained item variance (Table 8). Due to the large sample size, all DIF results were highly significant. For all 9 items, the direction of DIF was clear and consistent over most or all of the score range. Six items (PF02, moderate 
Table 6 Item-scale Correlations for the SF-36v2 - Saudi Arabia

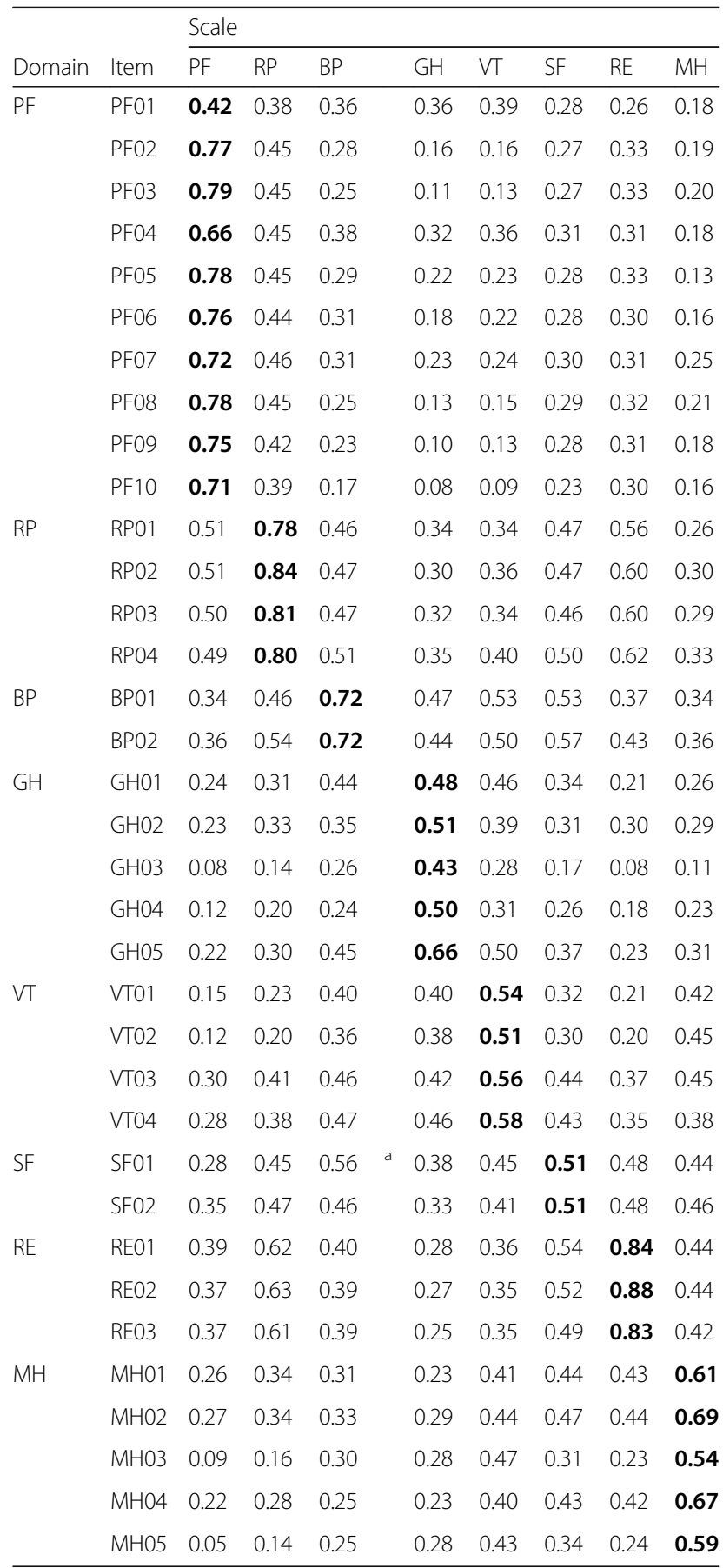

Numbers in bold show item-own-scale correlations

PF Physical function, RP Role Physical, BP Bodily Pain, GH General Health, VT Vitality, SF Social Function, RE Role Emotional, MH Mental Health

${ }^{a}$ Correlation with other scale is higher than correlation with own scale

activities; PF06, bending/kneeling; GH01, health in general; GH05, health is excellent; MH03, calm and peaceful; MH05, happy) provided a more positive assessment of health in Saudi Arabia compared to the anchor items. Three items (PF10, bathing or dressing; GH02, sick
Table 7 Hypothesized associations and observed factor loadings for a two-factor solution

\begin{tabular}{|c|c|c|c|c|c|c|}
\hline & \multicolumn{2}{|c|}{ Hypothesized associations } & \multicolumn{2}{|c|}{$\begin{array}{l}\text { Factor loadings } \\
\text { Varimax rotation }\end{array}$} & \multirow[b]{2}{*}{ Communality } & \multirow[b]{2}{*}{ Alpha } \\
\hline & Physical & Mental & Factor1 & Factor2 & & \\
\hline PF & $\bullet$ & $\circ$ & 0.80 & 0.07 & 0.64 & 0.92 \\
\hline $\mathrm{RP}$ & $\bullet$ & $\circ$ & 0.84 & 0.28 & 0.79 & 0.92 \\
\hline BP & $\bullet$ & $\circ$ & 0.43 & 0.64 & 0.60 & 0.81 \\
\hline GH & & & 0.15 & 0.72 & 0.55 & 0.75 \\
\hline VT & & & 0.14 & 0.85 & 0.74 & 0.75 \\
\hline SF & & $\bullet$ & 0.48 & 0.63 & 0.62 & 0.67 \\
\hline $\mathrm{RE}$ & $\circ$ & $\bullet$ & 0.74 & 0.33 & 0.65 & 0.93 \\
\hline $\mathrm{MH}$ & $\circ$ & $\bullet$ & 0.18 & 0.73 & 0.56 & 0.82 \\
\hline
\end{tabular}

PF Physical function, RP Role Physical, BP Bodily Pain, GH General Health, VT Vitality, SF Social Function, RE Role Emotional, MH Mental Health

-: Strong association (factor loading $\geq 0.6$ )

- : Moderate association $(0.3<$ factor loading $<0.6)$

$O$ : Weak association (factor loading $\leq 0.3$ )

Bold values indicate factor loadings $\geq 0.6$

Alpha: Cronbach's alpha

easier; RE03, did work less carefully) provided a more negative assessment of heath in Saudi Arabia compared to the anchor items.

\section{Normative data for Saudi Arabia and comparisons with the USA}

Compared to 2009 US general population norms, Saudi Arabia data showed lower scores for the RP, SF, and RE scales as well as for the MCS (Table 9). Slightly lower scores were also seen for the PF and $\mathrm{MH}$ scales, but these differences were below the suggested threshold for clinical significance. Adjusting for age and gender led to slightly larger differences for the scales reflecting physical health but had little impact on differences in scales reflecting mental health. Adjusting for DIF lowered the Saudi Arabia scores for PF, GH, MH, PCS and MCS, but provided higher scores for RE, thus slightly diminishing the difference between Saudi Arabia and the US on this scale.

Both in Saudi Arabia and in the USA, separate analyses by gender and age group (Tables 10 and 11) showed lower physical health scores for older age groups. However, this trend was most pronounced in the USA, so the strongest cross-national differences were seen in the younger age groups. Saudi Arabian women, 60 years or older, reported significantly better physical function than American women in the same age group.

Comparisons according to gender in the Saudi Arabian sample showed that women scored lower on several scales: BP, GH, VT, SF, RE, and MH as well as on MCS (Tables 10 and 11). However, except for VT, the score 
Table 8 Test of Differential Item Function (DIF) between Saudi and US SF-36v2 versions

\begin{tabular}{|c|c|c|c|c|}
\hline Item & Abbreviated text & $d R^{2}$ & DIF & DIF direction for SA \\
\hline PF01 & ... vigorous activities, such as running, lifting heavy objects, participating in strenuous sports? & 0.021 & & \\
\hline PF02 & ... moderate activities, such as moving a table, pushing a vacuum cleaner, bowling, or playing golf? & 0.045 & NU & $\uparrow$ \\
\hline PF03 & ... lifting or carrying groceries? & 0.020 & & \\
\hline PF04 & ... climbing several flights of stairs? & 0.014 & & \\
\hline PF05 & ... climbing one flight of stairs? & 0.018 & & \\
\hline PF06 & ... bending, kneeling, or stooping? & 0.121 & NU & $\uparrow$ \\
\hline PF07 & ... walking more than a mile? & 0.027 & & \\
\hline PF08 & ... walking several hundred yards? & 0.010 & & \\
\hline PF09 & ... walking one hundred yards? & 0.001 & & \\
\hline PF10 & $\ldots$ bathing or dressing yourself? & 0.035 & NU & $\downarrow$ \\
\hline RP01 & cut down on the amount of time & 0.010 & & \\
\hline RP02 & accomplished less than you would like & 0.008 & & \\
\hline RP03 & limited in the kind of work or other activities & 0.000 & & \\
\hline RP04 & difficulty performing the work or other activities & 0.000 & & \\
\hline BP01 & How much bodily pain have you had during the past 4 weeks? & 0.005 & & \\
\hline BP02 & how much did pain interfere with your normal work & 0.008 & & \\
\hline $\mathrm{GH} 01$ & In general, would you say your health is: & 0.088 & NU & $\uparrow$ \\
\hline $\mathrm{GH} 02$ & seem to get sick a little easier than other people & 0.039 & $\mathbf{U}$ & $\downarrow$ \\
\hline GH03 & as healthy as anybody I know & 0.001 & & \\
\hline $\mathrm{GH} 04$ & I expect my health to get worse & 0.001 & & \\
\hline GH05 & health is excellent & 0.058 & NU & $\uparrow$ \\
\hline VT01 & did you feel full of life? & 0.001 & & \\
\hline VT02 & did you have a lot of energy? & 0.011 & & \\
\hline VT03 & did you feel worn out? & 0.010 & & \\
\hline VT04 & did you feel tired? & 0.003 & & \\
\hline SF01 & your normal social activities with family, friends, neighbors, or groups? & 0.002 & & \\
\hline SF02 & your social activities (like visiting with friends, relatives, etc.)? & 0.003 & & \\
\hline RE01 & Cut down on the amount of time you spent on work or other activities & 0.004 & & \\
\hline RE02 & Accomplished less than you would like & 0.004 & & \\
\hline RE03 & Did work or other activities less carefully than usual & 0.031 & $\mathbf{U}$ & $\downarrow$ \\
\hline $\mathrm{MH} 01$ & been very nervous? & 0.000 & & \\
\hline $\mathrm{MHO2}$ & felt so down in the dumps that nothing could cheer you up? & 0.000 & & \\
\hline $\mathrm{MHO3}$ & felt calm and peaceful? & 0.052 & $\mathbf{U}$ & $\uparrow$ \\
\hline $\mathrm{MHO4}$ & felt downhearted and depressed? & 0.001 & & \\
\hline MH05 & been happy? & 0.034 & U & $\uparrow$ \\
\hline
\end{tabular}

$\mathrm{dR}^{2}$ : Increase in explained item variance by including DIF term, values $>0.03$ in bold, NU: non-uniform DIF, U: uniform DIF, $\uparrow:$ Item score in Saudi Arabia tended to be higher than would be expected from anchor items, $\downarrow$ : Item score in Saudi Arabia tended to be lower than would be expected from anchor items

differences were below the thresholds for clinical significance.

Among men in Saudi Arabia (Table 10), the strongest score differences across age groups were seen for the PF scale and PCS. Among women (Table 11), lower scores in older age groups were seen for the RP, BP, and VT scales and PCS, whereas other scales remained fairly constant across age.

\section{Discussion}

This nationwide study generally supported the content validity, construct validity, and reliability of a new Saudi version of the SF-36v2. In the qualitative study, participants emphasized physical and psychological function as important components of health - along with social function and healthy eating. Thus, similar to the World Health Organization (WHO) definition [23], health was 
Table 9 SF-36v2 Norm Tables for Saudi Arabia - Total Sample

\begin{tabular}{|c|c|c|c|c|c|c|c|c|c|c|}
\hline & PF & $\mathrm{RP}$ & $\mathrm{BP}$ & $\mathrm{GH}$ & VT & SF & RE & $\mathrm{MH}$ & PCS & MCS \\
\hline \multicolumn{11}{|l|}{ All } \\
\hline Mean & 48.73 & 46.42 & 50.09 & 50.58 & 49.79 & 46.18 & 43.18 & 47.27 & 50.32 & 45.36 \\
\hline Std Dev & 10.13 & 9.10 & 9.33 & 8.51 & 9.20 & 8.90 & 11.21 & 10.15 & 8.12 & 9.69 \\
\hline Minimum & 19.26 & 21.23 & 21.68 & 18.95 & 22.89 & 17.23 & 14.39 & 11.63 & 16.40 & 7.74 \\
\hline 25th Pctl & 44.15 & 39.19 & 42.64 & 46.05 & 43.69 & 42.30 & 35.28 & 40.40 & 44.82 & 39.17 \\
\hline 50th Pctl & 51.80 & 48.17 & 51.51 & 50.81 & 49.63 & 47.31 & 45.72 & 48.25 & 51.55 & 46.25 \\
\hline 75th Pctl & 57.54 & 54.91 & 55.55 & 56.99 & 55.57 & 52.33 & 56.17 & 56.10 & 56.72 & 52.47 \\
\hline Maximum & 57.54 & 57.16 & 62.00 & 66.50 & 70.42 & 57.34 & 56.17 & 63.95 & 72.45 & 73.18 \\
\hline N & 6164 & 6148 & 6150 & 6166 & 6149 & 6163 & 6135 & 6150 & 6136 & 6137 \\
\hline N Miss & 2 & 18 & 16 & 0 & 17 & 3 & 31 & 16 & 30 & 29 \\
\hline $\begin{array}{l}\text { ¿-USA } \\
\text { unadj } \\
(95 \% \mathrm{Cl})\end{array}$ & $\begin{array}{l}-1.27 \\
(-1.67 / \\
-0.87)\end{array}$ & $\begin{array}{l}-3.58 \\
(-3.96 / \\
-3.20)\end{array}$ & $\begin{array}{l}0.09(-0.29 / \\
0.47)\end{array}$ & $\begin{array}{l}0.58(0.22 / \\
0.94)\end{array}$ & $\begin{array}{l}-0.21 \\
(-0.59 / \\
0.16)\end{array}$ & $\begin{array}{l}-3.82 \\
(-4.20 / \\
-3.45)\end{array}$ & $\begin{array}{l}-6.82 \\
(-7.25 / \\
-6.40)\end{array}$ & $\begin{array}{l}-2.73(- \\
3.14 /-2.33)\end{array}$ & $\begin{array}{l}0.31(- \\
0.04 / 0.66)\end{array}$ & $\begin{array}{l}-4.65(- \\
5.04 /-4.26)\end{array}$ \\
\hline $\begin{array}{l}\delta \text {-USA adj } \\
(95 \% \mathrm{Cl})\end{array}$ & $\begin{array}{l}-2.70 \\
(-3.11 / \\
-2.28)\end{array}$ & $\begin{array}{l}-4.75(- \\
5.15 /-4.36)\end{array}$ & $\begin{array}{l}-0.96(- \\
1.36 /-0.56)\end{array}$ & $\begin{array}{l}0.04(- \\
0.35 / 0.43)\end{array}$ & $\begin{array}{l}-0.25(- \\
0.65 / 0.15)\end{array}$ & $\begin{array}{l}-4.23(- \\
4.63 /-3.84)\end{array}$ & $\begin{array}{l}-7.15(- \\
7.60 /-6.69)\end{array}$ & $\begin{array}{l}-2.44(- \\
2.87 /-2.01)\end{array}$ & $\begin{array}{l}-1.18(- \\
1.55 /-0.82)\end{array}$ & $\begin{array}{l}-4.18(- \\
4.59 /-3.76)\end{array}$ \\
\hline $\begin{array}{l}\delta \text {-USA DIF } \\
\text { adj }(95 \% \mathrm{Cl})\end{array}$ & $\begin{array}{l}-\mathbf{3 . 1 0}(- \\
3.51 /-2.70)\end{array}$ & & & $\begin{array}{l}-1.83 \\
(-2.20 / \\
-1.47)\end{array}$ & & & $\begin{array}{l}-\mathbf{5 . 6 7}(- \\
6.10 /-5.23)\end{array}$ & $\begin{array}{l}-\mathbf{4 . 8 2} \\
(-5.25 /- \\
4.38)\end{array}$ & $\begin{array}{l}-\mathbf{- 1 . 5 8} \\
(-1.94 /- \\
1.22)\end{array}$ & $\begin{array}{l}-4.57(- \\
4.98 /-4.16)\end{array}$ \\
\hline
\end{tabular}

Figures in BOLD indicate our best assessment of crossnational differences

$\delta$-USA unadj: Difference between Saudi and US SF-36v2 scores without adjustment

$\delta$-USA adj: Difference between Saudi and US SF-36v2 scores with adjustment for differences in age and gender

$\delta$-USA DIF adj: Difference between Saudi and US SF-36v2 scores with adjustment for differential item function and differences in age and gender

95\% CI 95\% confidence interval, PF Physical function, RP Role Physical, BP Bodily Pain, GH General Health, VT Vitality, SF Social Function, RE Role Emotional, MH Mental Health

seen as having both physical, psychological and social aspects. Most of the important HRQOL outcomes listed by participants overlap with domains covered by SF-36. However, some domains mentioned by smaller proportions of participants are not covered by the SF-36: religious habits, eating habits, travel, good sleep, and sexual function. Items covering these domains have been developed and will be reported in future papers.

Cognitive debriefing of the Saudi SF-36v2 indicated that respondents found the questionnaire easy to understand and answer. Each survey item was rated as relevant by more than $90 \%$ of participants, supporting the content validity of the survey.

The psychometric analyses supported the reliability and validity of the SF-36v2 in a Saudi general population. All items showed satisfactory convergence within scales. In all but one instance, items also showed satisfactory differentiation across scales. Such results are on par with results from the original validation of the SF-36 in the US [29]. Overall, these results support the hypothesized scale structure of the Saudi Arabic SF-36v2. However, exploratory factor analyses did not find a factor solution similar to typical results from Western countries [31]. Rather, the two-factor solution resembled results previously found in a Japanese sample [32] and to some extent in a Turkish urban population [21]. In contrast, factor analytic results from a study in Lebanon more closely resembled typical results from western countries [7]. The factor solution in our study seems particularly driven by the high correlation between the $\mathrm{RP}$ and RE scales, which suggest that the distinction between physical and psychological reasons for poor role performance does not apply to the Saudi data. The implications of these results for the validity of the PCS and MCS scores in Saudi Arabia needs to be explored in future studies.

Seven of the SF-36v2 scales had internal consistency reliability above 0.70 , but the two-item SF scale had a reliability of only 0.67 . However, this scale has also shown low reliability in some US studies, e.g., the first US general population study, where the SF scales showed a reliability of 0.63 [41]. Thus, the reliability results may be considered as adequate.

Within Saudi Arabia, we found no DIF for age and gender, but we found cross-national DIF for 9 items when comparing with US general population data. In a post-hoc cognitive debriefing study of these 9 items we were not able to identify problems in these 9 items that might explain the DIF (data not shown). A possible explanation of the DIF may be cultural or lifestyle differences between Saudi Arabia and the USA. For example, because of religious practices, persons in Saudi Arabia may do more bending and kneeling and thus find this activity easier than persons in the USA. The item on 
Table 10 SF-36v2 Norm Tables for Saudi Arabia - Age Groups - Male

\begin{tabular}{|c|c|c|c|c|c|c|c|c|c|c|}
\hline & PF & $\mathrm{RP}$ & $\mathrm{BP}$ & $\mathrm{GH}$ & VT & SF & RE & $\mathrm{MH}$ & PCS & MCS \\
\hline \multicolumn{11}{|l|}{$15-29$ Years } \\
\hline Mean & 49.94 & 47.33 & 51.99 & 51.62 & 51.25 & 47.29 & 45.22 & 47.96 & 51.49 & 46.62 \\
\hline Std Dev & 10.39 & 9.60 & 9.61 & 8.68 & 8.75 & 9.03 & 11.61 & 9.80 & 8.07 & 9.27 \\
\hline Minimum & 19.26 & 21.23 & 21.68 & 18.95 & 22.89 & 17.23 & 14.39 & 11.63 & 22.82 & 11.46 \\
\hline 25th Pctl & 46.06 & 39.19 & 46.27 & 46.05 & 46.66 & 42.30 & 35.28 & 40.40 & 46.17 & 40.67 \\
\hline 50th Pctl & 55.63 & 48.17 & 51.51 & 52.23 & 52.60 & 47.31 & 45.72 & 50.87 & 52.99 & 47.69 \\
\hline 75th Pctl & 57.54 & 57.16 & 62.00 & 57.94 & 58.54 & 57.34 & 56.17 & 56.10 & 57.93 & 53.15 \\
\hline Maximum & 57.54 & 57.16 & 62.00 & 66.50 & 70.42 & 57.34 & 56.17 & 63.95 & 68.30 & 69.98 \\
\hline N & 1265 & 1263 & 1264 & 1266 & 1264 & 1265 & 1260 & 1264 & 1262 & 1263 \\
\hline N Miss & 1 & 3 & 2 & 0 & 2 & 1 & 6 & 2 & 4 & 3 \\
\hline $\begin{array}{l}\delta \text {-USA } \\
\text { unadj } \\
(95 \% \mathrm{Cl})\end{array}$ & $\begin{array}{l}-5.63 \\
(-6.73 / \\
-4.52)\end{array}$ & $\begin{array}{l}-7.23 \\
(-8.28 /- \\
6.19)\end{array}$ & $\begin{array}{l}-2.93(- \\
4.01 /-1.86)\end{array}$ & $\begin{array}{l}-2.19(- \\
3.21 /-1.17)\end{array}$ & $\begin{array}{l}-0.99(- \\
2.03 / 0.04)\end{array}$ & $\begin{array}{l}-4.72(- \\
5.75 /-3.68)\end{array}$ & $\begin{array}{l}-7.58 \\
(-8.85 / \\
-6.32)\end{array}$ & $\begin{array}{l}-3.07(- \\
4.20 /-1.95)\end{array}$ & $\begin{array}{l}-4.28(- \\
5.17 /-3.39)\end{array}$ & $\begin{array}{l}-3.76(- \\
4.82 /-2.70)\end{array}$ \\
\hline $\begin{array}{l}\delta \text {-USA DIF } \\
\operatorname{adj}(95 \% \mathrm{Cl})\end{array}$ & $\begin{array}{l}-5.96 \\
(-7.03 / \\
-4.89)\end{array}$ & & & $\begin{array}{l}-4.15 \\
(-5.10 / \\
-3.20)\end{array}$ & & & $\begin{array}{l}-6.38 \\
(-7.56 / \\
-5.19)\end{array}$ & $\begin{array}{l}-5.42 \\
(-6.58 / \\
-4.27)\end{array}$ & $\begin{array}{l}-4.62(- \\
5.50 /-3.75)\end{array}$ & $\begin{array}{l}-4.28 \\
(-5.32 /- \\
3.23)\end{array}$ \\
\hline \multicolumn{11}{|l|}{ 30-44 Years } \\
\hline Mean & 48.45 & 46.41 & 50.84 & 51.91 & 51.37 & 46.56 & 44.08 & 48.10 & 50.47 & 46.63 \\
\hline Std Dev & 10.74 & 9.15 & 9.39 & 8.43 & 8.89 & 8.92 & 11.21 & 9.48 & 8.13 & 9.37 \\
\hline Minimum & 19.26 & 21.23 & 21.68 & 18.95 & 22.89 & 17.23 & 14.39 & 11.63 & 22.82 & 8.57 \\
\hline 25th Pctl & 42.23 & 39.19 & 42.64 & 47.48 & 46.66 & 42.30 & 35.28 & 43.02 & 44.81 & 40.66 \\
\hline 50th Pctl & 53.71 & 48.17 & 51.51 & 53.19 & 52.60 & 47.31 & 45.72 & 50.87 & 51.80 & 47.22 \\
\hline 75th Pctl & 57.54 & 54.91 & 62.00 & 57.94 & 58.54 & 52.33 & 56.17 & 56.10 & 56.89 & 53.46 \\
\hline Maximum & 57.54 & 57.16 & 62.00 & 66.50 & 70.42 & 57.34 & 56.17 & 63.95 & 72.45 & 69.84 \\
\hline N & 804 & 801 & 801 & 804 & 801 & 804 & 799 & 802 & 799 & 799 \\
\hline N Miss & 0 & 3 & 3 & 0 & 3 & 0 & 5 & 2 & 5 & 5 \\
\hline $\begin{array}{l}\delta \text {-USA } \\
\text { unadj } \\
(95 \% \mathrm{Cl})\end{array}$ & $\begin{array}{l}-5.10 \\
(-6.17 / \\
-4.03)\end{array}$ & $\begin{array}{l}-6.47 \\
(-7.46 / \\
-5.49)\end{array}$ & $\begin{array}{l}-1.51(- \\
2.56 /-0.46)\end{array}$ & $\begin{array}{l}0.31(- \\
0.66 / 1.29)\end{array}$ & $\begin{array}{l}-0.13(- \\
1.15 / 0.90)\end{array}$ & $\begin{array}{l}-5.15(- \\
6.17 /-4.13)\end{array}$ & $\begin{array}{l}-7.32 \\
(-8.51 / \\
-6.13)\end{array}$ & $\begin{array}{l}-2.02(- \\
3.13 /-0.91)\end{array}$ & $\begin{array}{l}-2.93(- \\
3.79 /-2.06)\end{array}$ & $\begin{array}{l}-3.42 \\
(-4.51 / \\
-2.33)\end{array}$ \\
\hline $\begin{array}{l}\delta \text {-USA DIF } \\
\text { adj }(95 \% \mathrm{Cl})\end{array}$ & $\begin{array}{l}-5.42(- \\
6.46 /-4.39)\end{array}$ & & & $\begin{array}{l}-1.71 \\
(-2.63 / \\
-0.78)\end{array}$ & & & $\begin{array}{l}-5.96 \\
(-7.09 /- \\
4.83)\end{array}$ & $\begin{array}{l}-4.35 \\
(-5.48 /- \\
3.22)\end{array}$ & $\begin{array}{l}-3.31(- \\
4.17 /-2.46)\end{array}$ & $\begin{array}{l}-3.86 \\
(-4.94 /- \\
2.78)\end{array}$ \\
\hline \multicolumn{11}{|l|}{ 45-59 Years } \\
\hline Mean & 48.42 & 46.54 & 50.83 & 50.73 & 50.97 & 46.49 & 43.85 & 47.67 & 50.29 & 46.19 \\
\hline Std Dev & 10.58 & 9.27 & 9.07 & 8.80 & 8.61 & 8.52 & 11.42 & 9.43 & 7.58 & 9.10 \\
\hline Minimum & 19.26 & 21.23 & 21.68 & 18.95 & 22.89 & 17.23 & 14.39 & 14.24 & 22.82 & 7.74 \\
\hline 25th Pctl & 44.15 & 39.19 & 46.27 & 46.05 & 46.66 & 42.30 & 35.28 & 40.40 & 45.35 & 40.38 \\
\hline 50th Pctl & 51.80 & 48.17 & 51.51 & 50.81 & 49.63 & 47.31 & 45.72 & 48.25 & 51.09 & 46.99 \\
\hline 75th Pctl & 57.54 & 57.16 & 62.00 & 56.99 & 58.54 & 52.33 & 56.17 & 56.10 & 56.18 & 52.87 \\
\hline Maximum & 57.54 & 57.16 & 62.00 & 66.50 & 70.42 & 57.34 & 56.17 & 63.95 & 68.30 & 73.18 \\
\hline N & 514 & 514 & 512 & 514 & 514 & 514 & 511 & 514 & 514 & 514 \\
\hline N Miss & 0 & 0 & 2 & 0 & 0 & 0 & 3 & 0 & 0 & 0 \\
\hline $\begin{array}{l}\delta \text {-USA } \\
\text { unadj } \\
(95 \% \mathrm{Cl})\end{array}$ & $\begin{array}{l}-1.67 \\
(-2.87 / \\
-0.46)\end{array}$ & $\begin{array}{l}-2.65 \\
(-3.84 / \\
-1.47)\end{array}$ & $\begin{array}{l}2.17 \text { (0.99/ } \\
3.35)\end{array}$ & $\begin{array}{l}2(0.87 / \\
3.12)\end{array}$ & $\begin{array}{l}-0.05 \\
(-1.16 / \\
1.05)\end{array}$ & $\begin{array}{l}-3.03 \\
(-4.18 / \\
-1.88)\end{array}$ & $\begin{array}{l}-6.11 \\
(-7.38 / \\
-4.84)\end{array}$ & $\begin{array}{l}-2.56(- \\
3.75 /-1.37)\end{array}$ & $\begin{array}{l}1.31(0.24 / \\
2.37)\end{array}$ & $\begin{array}{l}-4.28 \\
(-5.44 / \\
-3.13)\end{array}$ \\
\hline $\begin{array}{l}\delta \text {-USA DIF } \\
\text { adj }(95 \% \mathrm{Cl})\end{array}$ & $\begin{array}{l}-2.05 \\
(-3.23 / \\
-0.88)\end{array}$ & & & $\begin{array}{l}0.11(- \\
0.97 / 1.19)\end{array}$ & & & $\begin{array}{l}-4.74 \\
(-5.97 /- \\
3.52)\end{array}$ & $\begin{array}{l}-4.93 \\
(-6.14 /- \\
3.72)\end{array}$ & $\begin{array}{l}0.94(-0.12 / \\
2.00)\end{array}$ & $\begin{array}{l}-4.73 \\
(-5.88 /- \\
3.58)\end{array}$ \\
\hline
\end{tabular}


Table 10 SF-36v2 Norm Tables for Saudi Arabia - Age Groups - Male (Continued)

\begin{tabular}{|c|c|c|c|c|c|c|c|c|c|c|}
\hline & PF & $\mathrm{RP}$ & $\mathrm{BP}$ & $\mathrm{GH}$ & VT & SF & RE & $\mathrm{MH}$ & PCS & MCS \\
\hline \multicolumn{11}{|l|}{$60+$ Years } \\
\hline Mean & 46.63 & 45.39 & 49.64 & 50.49 & 51.37 & 45.55 & 44.49 & 48.72 & 48.43 & 47.42 \\
\hline Std Dev & 11.65 & 9.35 & 9.81 & 9.42 & 9.25 & 9.56 & 11.01 & 10.25 & 8.67 & 9.61 \\
\hline Minimum & 19.26 & 21.23 & 25.71 & 18.95 & 22.89 & 17.23 & 14.39 & 11.63 & 25.20 & 16.54 \\
\hline 25th Pctl & 40.32 & 39.19 & 42.24 & 43.68 & 46.66 & 37.29 & 35.28 & 40.40 & 41.29 & 40.92 \\
\hline 50th Pctl & 49.88 & 45.93 & 51.51 & 52.23 & 52.60 & 47.31 & 45.72 & 50.87 & 50.20 & 48.43 \\
\hline 75th Pctl & 55.63 & 54.91 & 55.55 & 57.94 & 58.54 & 52.33 & 56.17 & 58.72 & 55.38 & 55.15 \\
\hline Maximum & 57.54 & 57.16 & 62.00 & 66.50 & 70.42 & 57.34 & 56.17 & 63.95 & 64.78 & 64.48 \\
\hline N & 216 & 213 & 214 & 216 & 215 & 216 & 214 & 215 & 213 & 213 \\
\hline N Miss & 0 & 3 & 2 & 0 & 1 & 0 & 2 & 1 & 3 & 3 \\
\hline $\begin{array}{l}\delta \text {-USA unadj } \\
(95 \% \mathrm{Cl})\end{array}$ & $\begin{array}{l}0.52(-0.95 / \\
2.00)\end{array}$ & $\begin{array}{l}-1.04 \\
(-2.44 / \\
0.36)\end{array}$ & $\begin{array}{l}1.09(-0.23 / \\
2.42)\end{array}$ & $\begin{array}{l}1.81(0.49 / \\
3.13)\end{array}$ & $\begin{array}{l}0.14(- \\
1.17 / 1.45)\end{array}$ & $\begin{array}{l}-5.12 \\
(-6.42 / \\
-3.83)\end{array}$ & $\begin{array}{l}-6.03 \\
(-7.35 / \\
-4.72)\end{array}$ & $\begin{array}{l}-4.65(- \\
5.86 /-3.44)\end{array}$ & $\begin{array}{l}2.92(1.54 / \\
4.29)\end{array}$ & $\begin{array}{l}-6.41 \\
(-7.60 / \\
-5.21)\end{array}$ \\
\hline $\begin{array}{l}\delta \text {-USA DIF } \\
\text { adj }(95 \% \text { Cl) }\end{array}$ & $\begin{array}{l}0.25(-1.19 / \\
1.70)\end{array}$ & & & $\begin{array}{l}-0.01(- \\
1.29 / 1.26)\end{array}$ & & & $\begin{array}{l}-4.69 \\
(-5.96 / \\
-3.42)\end{array}$ & $\begin{array}{l}-6.97 \\
(-8.19 /- \\
5.74)\end{array}$ & $\begin{array}{l}2.61(1.24 / \\
3.97)\end{array}$ & $\begin{array}{l}-6.86 \\
(-8.04 /- \\
5.67)\end{array}$ \\
\hline
\end{tabular}

ס-USA unadj: Difference between Saudi and US SF-36v2 scores without adjustment

$\delta$-USA DIF adj: Difference between Saudi and US SF-36v2 scores with adjustment for differential item function

95\% Cl 95\% confidence interval, PF Physical function, RP Role Physical, BP Bodily Pain, GH General Health, VT Vitality, SF Social Function, RE Role Emotional, MH Mental Health

bending and kneeling is still a valid indicator of physical function in each country, but the item is easier for persons in Saudi Arabia, thus influencing comparisons of Physical Function. If the interest of the researcher is to compare physical function in general (and not the specific activity of bending/kneeling) the comparison can be adjusted for the DIF. The impact of such adjustments can be evaluated on the overall level in Table 9 and for age and gender subgroups in Tables 10 and 11 . The impact is actually rather small for the PF scale (0.40), but larger for the $\mathrm{GH}$ (1.87) and $\mathrm{MH}$ (2.38) scales. While these impacts are smaller than the MID for each scale, the largest impacts are larger than the impact of adjustment for demographic differences. Therefore, we recommend considering DIF when interpreting cross-national comparisons between Saudi Arabia and the USA.

After adjustment for differences in age and gender, as well as DIF, analysis of Saudi general population norm data showed low scores for scales concerning physical function (PF difference $=-3.10$ ), role and social function $(\mathrm{RP}$ difference $=-4.75, \mathrm{SF}$ difference $=-4.23$, and $\mathrm{RE}$ difference $=-5.67)$, mental health $(\mathrm{MH}$ difference $=-$ 4.82) as well as for the mental component summary (MCS difference $=-4.57)$ compared to US general population norms (Table 9). In particular, scores on the RE scale were lower for women in Saudi Arabia compared to the USA, although some of this difference was explained by DIF. These differences are not likely to be caused by higher morbidity in Saudi Arabia since the self-reported prevalence of many chronic conditions was lower in Saudi Arabia than in the USA. The magnitude of the differences on these scales suggests differences in function that need to be explored. In particular, the lower scores in scales relating to mental health (SF, RE, $\mathrm{MH}$, and MCS) does not concur with the low reports of clinical anxiety and depression (Table 5). A large study (1990-2013) to estimate the burden of mental disorders in the Eastern Mediterranean Region including Saudi Arabia, reported that the stigma attached to mental illness may cause underreporting or waiting for a long period of time before seeking healthcare [42]. Thus, it is possible that clinical anxiety and depression is underdiagnosed or under-reported for cultural reasons. Further, the low score on scales related to mental health may reflect subclinical, rather than clinical, mental health problems.

As in previous general population studies (e.g. $[3,4,9,10])$, women scored lower on all SF-36v2 scales, thus supporting known groups validity. However, the average differences were often small - only the gender difference for the vitality scale exceeded the threshold for clinical significance.

Analyses by age group found lower scores in older age groups for SF-36v2 scales concerning physical health: PF, RP, BP, and PCS. These results are in line with results from many other studies $[3,4,9,10]$, reflecting a decline in physical function with age and thus supporting known groups validity. As in previous studies, measures reflecting mental health were relatively constant across age groups. A study by Lorem et al. [43] found age by itself was protective of mental health symptoms when controlled for the mental health symptoms associated with physical illness. 
Table 11 SF-36v2 Norm Tables for Saudi Arabia - Age Groups - Female

\begin{tabular}{|c|c|c|c|c|c|c|c|c|c|c|}
\hline & PF & $\mathrm{RP}$ & $\mathrm{BP}$ & $\mathrm{GH}$ & VT & SF & $\mathrm{RE}$ & $\mathrm{MH}$ & PCS & MCS \\
\hline \multicolumn{11}{|l|}{$15-29$ Years } \\
\hline Mean & 49.13 & 46.70 & 49.78 & 50.16 & 48.98 & 46.20 & 42.17 & 46.99 & 50.60 & 44.52 \\
\hline Std Dev & 9.53 & 8.61 & 8.90 & 8.20 & 9.28 & 8.62 & 10.98 & 10.36 & 7.91 & 9.82 \\
\hline Minimum & 19.26 & 21.23 & 21.68 & 18.95 & 22.89 & 17.23 & 14.39 & 11.63 & 16.89 & 8.33 \\
\hline 25th Pctl & 46.06 & 39.19 & 42.64 & 46.05 & 43.69 & 42.30 & 35.28 & 40.40 & 45.04 & 38.02 \\
\hline 50th Pctl & 51.80 & 48.17 & 50.71 & 50.81 & 49.63 & 47.31 & 45.72 & 48.25 & 51.96 & 45.30 \\
\hline 75th Pctl & 55.63 & 54.91 & 55.55 & 55.56 & 55.57 & 52.33 & 52.69 & 56.10 & 56.88 & 51.89 \\
\hline Maximum & 57.54 & 57.16 & 62.00 & 66.50 & 70.42 & 57.34 & 56.17 & 63.95 & 69.64 & 66.24 \\
\hline$N$ & 1678 & 1672 & 1673 & 1678 & 1675 & 1677 & 1670 & 1675 & 1671 & 1671 \\
\hline N Miss & 0 & 6 & 5 & 0 & 3 & 1 & 8 & 3 & 7 & 7 \\
\hline $\begin{array}{l}\delta \text {-USA } \\
\text { unadj } \\
(95 \% \mathrm{Cl})\end{array}$ & $\begin{array}{l}-3.78 \\
(-4.73 / \\
-2.83)\end{array}$ & $\begin{array}{l}-5.65 \\
(-6.52 / \\
-4.78)\end{array}$ & $\begin{array}{l}-2.75(- \\
3.67 /-1.84)\end{array}$ & $\begin{array}{l}-0.44 \\
(-1.31 / \\
0.43)\end{array}$ & $\begin{array}{l}0.93(- \\
0.05 / 1.90)\end{array}$ & $\begin{array}{l}-3.51 \\
(-4.43 / \\
-2.59)\end{array}$ & $\begin{array}{l}-7.02 \\
(-8.13 /- \\
5.90)\end{array}$ & $\begin{array}{l}-0.71 \\
(-1.78 / \\
0.35)\end{array}$ & $\begin{array}{l}-3.07(- \\
3.87 /-2.27)\end{array}$ & $\begin{array}{l}-2.26 \\
(-3.30 /- \\
1.22)\end{array}$ \\
\hline $\begin{array}{l}\delta \text {-USA DIF } \\
\text { adj }(95 \% \mathrm{Cl})\end{array}$ & $\begin{array}{l}-4.22(- \\
5.13 /-3.31)\end{array}$ & & & $\begin{array}{l}-2.29 \\
(-3.10 / \\
-1.49)\end{array}$ & & & $\begin{array}{l}-5.44 \\
(-6.49 / \\
-4.38)\end{array}$ & $\begin{array}{l}-3.13(- \\
4.23 /-2.03)\end{array}$ & $\begin{array}{l}-3.49 \\
(-4.28 /- \\
2.70)\end{array}$ & $\begin{array}{l}-2.62 \\
(-3.65 /- \\
1.59)\end{array}$ \\
\hline \multicolumn{11}{|l|}{ 30-44 Years } \\
\hline Mean & 48.36 & 45.99 & 48.59 & 49.38 & 47.88 & 45.12 & 41.48 & 46.10 & 49.77 & 43.61 \\
\hline Std Dev & 9.41 & 8.70 & 8.94 & 8.44 & 9.30 & 8.99 & 10.90 & 10.63 & 8.01 & 10.04 \\
\hline Minimum & 19.26 & 21.23 & 21.68 & 18.95 & 22.89 & 17.23 & 14.39 & 11.63 & 17.76 & 11.10 \\
\hline 25th Pctl & 44.15 & 39.19 & 42.24 & 43.68 & 43.69 & 37.29 & 35.28 & 37.79 & 44.91 & 37.05 \\
\hline 50th Pctl & 51.80 & 48.17 & 46.68 & 49.86 & 46.66 & 47.31 & 42.24 & 45.64 & 50.77 & 44.39 \\
\hline 75th Pctl & 55.63 & 52.66 & 55.55 & 55.56 & 55.57 & 52.33 & 49.20 & 55.23 & 55.87 & 51.23 \\
\hline Maximum & 57.54 & 57.16 & 62.00 & 66.50 & 70.42 & 57.34 & 56.17 & 63.95 & 69.57 & 64.75 \\
\hline$N$ & 880 & 879 & 881 & 881 & 878 & 881 & 878 & 878 & 876 & 876 \\
\hline N Miss & 1 & 2 & 0 & 0 & 3 & 0 & 3 & 3 & 5 & 5 \\
\hline $\begin{array}{l}\delta \text {-USA } \\
\text { unadj } \\
(95 \% \mathrm{Cl})\end{array}$ & $\begin{array}{l}-3.65 \\
(-4.67 / \\
-2.63)\end{array}$ & $\begin{array}{l}-5.84 \\
(-6.81 /- \\
4.86)\end{array}$ & $\begin{array}{l}-2.31(- \\
3.33 /-1.29)\end{array}$ & $\begin{array}{l}-1.01(- \\
2.02 /-0.01)\end{array}$ & $\begin{array}{l}-0.75(- \\
1.80 / 0.31)\end{array}$ & $\begin{array}{l}-4.73(- \\
5.78 /-3.69)\end{array}$ & $\begin{array}{l}-8.11 \\
(-9.30 / \\
-6.92)\end{array}$ & $\begin{array}{l}-2.72(- \\
3.86 /-1.58)\end{array}$ & $\begin{array}{l}-2.41(- \\
3.32 /-1.49)\end{array}$ & $\begin{array}{l}-4.49 \\
(-5.61 /- \\
3.36)\end{array}$ \\
\hline $\begin{array}{l}\delta \text {-USA DIF } \\
\text { adj }(95 \% \mathrm{Cl})\end{array}$ & $\begin{array}{l}-4.17 \\
(-5.16 /- \\
3.18)\end{array}$ & & & $\begin{array}{l}-2.78(- \\
3.73 /-1.84)\end{array}$ & & & $\begin{array}{l}-6.46 \\
(-7.60 /- \\
5.31)\end{array}$ & $\begin{array}{l}-5.16(- \\
6.33 /-3.99)\end{array}$ & $\begin{array}{l}-2.85(- \\
3.75 /-1.95)\end{array}$ & $\begin{array}{l}-4.80(- \\
5.93 /-3.68)\end{array}$ \\
\hline \multicolumn{11}{|l|}{ 45-59 Years } \\
\hline Mean & 47.89 & 45.42 & 48.48 & 49.81 & 48.66 & 45.00 & 41.99 & 46.74 & 49.22 & 44.51 \\
\hline Std Dev & 9.28 & 8.81 & 9.38 & 8.21 & 9.58 & 8.85 & 10.35 & 10.12 & 8.14 & 9.37 \\
\hline Minimum & 19.26 & 21.23 & 21.68 & 23.71 & 22.89 & 17.23 & 14.39 & 11.63 & 21.40 & 14.76 \\
\hline 25th Pctl & 42.23 & 39.19 & 42.24 & 44.31 & 43.69 & 37.29 & 35.28 & 39.10 & 43.68 & 39.03 \\
\hline 50th Pctl & 51.80 & 45.93 & 50.71 & 50.81 & 46.66 & 47.31 & 45.72 & 48.25 & 50.49 & 45.31 \\
\hline 75th Pctl & 55.63 & 52.66 & 55.55 & 55.56 & 55.57 & 52.33 & 49.20 & 53.48 & 55.78 & 51.49 \\
\hline Maximum & 57.54 & 57.16 & 62.00 & 66.50 & 70.42 & 57.34 & 56.17 & 63.95 & 68.07 & 64.24 \\
\hline$N$ & 429 & 429 & 429 & 429 & 428 & 429 & 427 & 428 & 428 & 428 \\
\hline N Miss & 0 & 0 & 0 & 0 & 1 & 0 & 2 & 1 & 1 & 1 \\
\hline 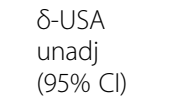 & $\begin{array}{l}0.85(-0.46 / \\
2.16)\end{array}$ & $\begin{array}{l}-2.42 \\
(-3.74 / \\
-1.10)\end{array}$ & $\begin{array}{l}1.88(0.56 / \\
3.20)\end{array}$ & $\begin{array}{l}1.74(0.45 / \\
3.03)\end{array}$ & $\begin{array}{l}0.55(- \\
0.79 / 1.89)\end{array}$ & $\begin{array}{l}-3.2 \\
(-4.51 / \\
-1.88)\end{array}$ & $\begin{array}{l}-6.22 \\
(-7.66 / \\
-4.77)\end{array}$ & $\begin{array}{l}-1.46 \\
(-2.84 / \\
-0.07)\end{array}$ & $\begin{array}{l}2.06(0.81 / \\
3.31)\end{array}$ & $\begin{array}{l}-4.23 \\
(-5.58 /- \\
2.89)\end{array}$ \\
\hline $\begin{array}{l}\delta \text {-USA DIF } \\
\text { adj }(95 \% \mathrm{Cl})\end{array}$ & $\begin{array}{l}0.37(-0.92 / \\
1.65)\end{array}$ & & & $\begin{array}{l}-0.11 \\
(-1.36 / 1.14)\end{array}$ & & & $\begin{array}{l}-4.57(- \\
5.98 /-3.16)\end{array}$ & $\begin{array}{l}-3.84(- \\
5.24 /-2.43)\end{array}$ & $\begin{array}{l}1.61(0.36 / \\
2.85)\end{array}$ & $\begin{array}{l}-4.54(- \\
5.88 /-3.19)\end{array}$ \\
\hline
\end{tabular}


Table 11 SF-36v2 Norm Tables for Saudi Arabia - Age Groups - Female (Continued)

\begin{tabular}{|c|c|c|c|c|c|c|c|c|c|c|}
\hline & PF & $\mathrm{RP}$ & $\mathrm{BP}$ & $\mathrm{GH}$ & VT & SF & RE & $\mathrm{MH}$ & PCS & MCS \\
\hline \multicolumn{11}{|l|}{$60+$ Years } \\
\hline Mean & 46.27 & 42.98 & 46.12 & 48.79 & 46.66 & 43.88 & 40.57 & 45.97 & 47.08 & 43.64 \\
\hline Std Dev & 10.76 & 10.11 & 9.80 & 8.90 & 9.78 & 9.75 & 10.95 & 10.76 & 10.02 & 10.53 \\
\hline Minimum & 19.26 & 21.23 & 21.68 & 26.08 & 22.89 & 17.23 & 14.39 & 11.63 & 16.40 & 11.42 \\
\hline 25th Pctl & 41.00 & 36.95 & 38.21 & 43.68 & 40.72 & 37.29 & 35.28 & 37.79 & 42.53 & 36.92 \\
\hline 50th Pctl & 48.93 & 41.44 & 46.68 & 50.81 & 46.66 & 42.30 & 38.76 & 48.25 & 47.99 & 42.85 \\
\hline 75th Pctl & 55.63 & 52.66 & 51.51 & 55.09 & 52.60 & 52.33 & 45.72 & 53.48 & 54.25 & 50.88 \\
\hline Maximum & 57.54 & 57.16 & 62.00 & 66.50 & 67.45 & 57.34 & 56.17 & 63.95 & 65.20 & 66.07 \\
\hline N & 168 & 167 & 168 & 168 & 168 & 168 & 167 & 168 & 167 & 167 \\
\hline N Miss & 0 & 1 & 0 & 0 & 0 & 0 & 1 & 0 & 1 & 1 \\
\hline 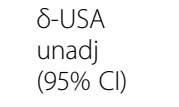 & $\begin{array}{l}3.18(1.42 / \\
4.94)\end{array}$ & $\begin{array}{l}-2.27 \\
(-3.97 / \\
-0.57)\end{array}$ & $\begin{array}{l}-0.54 \\
(-2.09 / \\
1.01)\end{array}$ & $\begin{array}{l}-0.17 \\
(-1.72 / \\
1.38)\end{array}$ & $\begin{array}{l}-3.2 \\
(-4.76 / \\
-1.64)\end{array}$ & $\begin{array}{l}-5.16 \\
(-6.72 / \\
-3.60)\end{array}$ & $\begin{array}{l}-8.54 \\
(-10.17 / \\
-6.91)\end{array}$ & $\begin{array}{l}-5.59 \\
(-7.10 / \\
-4.07)\end{array}$ & $\begin{array}{l}3.17(1.47 / \\
4.86)\end{array}$ & $\begin{array}{l}-8.94 \\
(-10.48 / \\
-7.41)\end{array}$ \\
\hline $\begin{array}{l}\delta \text {-USA DIF } \\
\text { adj }(95 \% \text { Cl) }\end{array}$ & $\begin{array}{l}2.76(1.03 / \\
4.50)\end{array}$ & & & $\begin{array}{l}-1.92 \\
(-3.43 / \\
-0.41)\end{array}$ & & & $\begin{array}{l}-6.84 \\
(-8.44 / \\
-5.23)\end{array}$ & $\begin{array}{l}-7.99 \\
(-9.52 / \\
-6.46)\end{array}$ & $\begin{array}{l}2.75(1.07 / \\
4.43)\end{array}$ & $\begin{array}{l}-9.25(- \\
10.77 /- \\
7.72)\end{array}$ \\
\hline
\end{tabular}

$\delta$-USA unadj: Difference between Saudi and US SF-36v2 scores without adjustment

$\delta$-USA DIF adj: Difference between Saudi and US SF-36v2 scores with adjustment for differential item function

95\% CI 95\% confidence interval, PF Physical function, RP Role Physical, BP Bodily Pain, GH General Health, VT Vitality, SF Social Function, RE Role Emotional, MH Mental Health

Representation from most regions of Saudi Arabia was satisfactory, but few participants were recruited from the Northern region. We ascribe these difficulties in recruiting participants to lack of familiarity and lack of acceptance of surveys in some parts of the Saudi culture. The Northern region is the smallest $(285,733$ Saudi inhabitants in 2016) and least densely populated region in Saudi Arabia, with a population that is slightly younger (mean age 26.1 years against 27.4 years for all of Saudi Arabia) and with a slightly lower proportion of mean (50,3\% against $50.9 \%)$. However, since these differences are very small, the low proportion of participants from the Northern region is unlikely to have a noticeable impact on the overall results.

\section{Conclusion}

This is the first large scale Saudi general population study of patient reported outcomes. We used a new translation of a well-known patient reported outcomes instrument, the SF-36v2. Concept elicitation, cognitive debriefing, and large-scale quantitative testing supported the validity and reliability of the Saudi SF-36v2, but an exploratory factor analysis did not support the typical distinction between a physical health and a mental health component. Also, we found cross-national DIF for 9 out of 35 tested items. After adjustment for DIF and demographic differences we found lower patient reported outcomes scores in Saudi Arabia for the PF, RP, $\mathrm{SF}, \mathrm{RE}$ and MH scales as well as for the MCS. For the $\mathrm{BP}, \mathrm{GH}$ and VT scales, as well as for PCS, score differences were smaller and did not exceed MID. Reasons for the differences in patient reported outcomes should be further explored and these general population differences should be taken into account when interpreting patient reported outcomes scores for patients in Saudi Arabia.

\section{Abbreviations}

HRQOL: Health-related Quality of Life; IQOLA: International Quality of Life Assessment; SF-36v2: Short Form Health Survey; DIF: Differential item function; PRO: Patient-reported outcome; IRT: Item response theory; MID: Minimally important difference; WHO: World Health Organization; MCS: The Mental Component Summary; PCS: The Physical Component Summary; MH: Mental Health; RE: Role limitations due to Emotional Problems; SF: Social Function; VT: Vitality; GH: General Health Perception; BP: Bodily Pain; RP: Role Limitations due to Physical Health; PF: Physical Function; US: United States

\section{Acknowledgments}

We acknowledge Dr. Youssef Al Tannir's help in editing the manuscript.

\section{Authors' contributions}

AA, QH contributed to the development of study design. AA, QH oversaw data collection. AA, QH, JB and MT made contributions to the data analysis and results interpretation. $\mathrm{AA}, \mathrm{QH}$ wrote the first draft of the manuscript. All authors contributed and made revisions to the interpretation of results, first draft, and the manuscript. All authors have read and approved the final manuscript.

\section{Funding}

This study was funded by King Abdul Aziz City for Science and Technology (T-K-12-1041).

\section{Availability of data and materials}

The datasets/tables used and/or analyzed during the current study are available from the author on reasonable request.

Ethics approval and consent to participate

The study protocol was reviewed and approved by the institutional review board at King Fahd Medical City Riyadh, KSA and conducted in compliance 
with the Declaration of Helsinki. Informed consent was obtained from each individual participants included in the study.

\section{Consent for publication}

Not applicable.

\section{Competing interests}

The authors declare that they have no competing of interests.

\section{Author details}

${ }^{1}$ Consultant Rehabilitation Hospital, King Fahad Medical City, Riyadh, Kingdom of Saudi Arabia. ${ }^{2}$ Rehabilitation Hospital, King Fahad Medical City, Riyadh, Kingdom of Saudi Arabia. ${ }^{3}$ Optum Outcomes, Johnston, RI, USA. ${ }^{4}$ Research Center, King Fahad Medical City, PO Box 59046, Riyadh 11525 , Kingdom of Saudi Arabia.

\section{Received: 20 January 2020 Accepted: 3 August 2020}

Published online: 13 August 2020

\section{References}

1. Khader, S., Hourani, M. M., \& Al-Akour, N. (2011). Normative data and psychometric properties of short form 36 health survey (SF-36, version 1.0) in the population of North Jordan. Eastern Mediterranean Health Journal, 17(5), 368-374..

2. Wagner, A. K., Gandek, B., Aaronson, N. K., Acquadro, C., Alonso, J., Apolone, G., et al. (1998). Cross-cultural comparisons of the content of SF-36 translations across 10 countries: Results from the IQOLA project. Journal of Clinical Epidemiology, 51(11), 925-932.

3. Ware, J. E., Kosinski, M., \& Gandel, B. (2000). SF-36 $6^{\oplus}$ health survey: Manual and interpretation guide. Lincoln: QualityMetric.

4. Hopman, W. M., Towheed, T., Anastassiades, T., Tenenhouse, A., Poliquin, S., Berger, C., et al. (2000). Canadian normative data for the SF-36 health survey. Canadian Medical Association Journal, 163(3), 265-271.

5. Wood-Dauphinee, S. (2000). The Canadian SF-36 health survey: Normative data add to its value. Canadian Medical Association Journal, 163(3), 283-284.

6. Lam, C. L., Lauder, I. J., Lam, T. P., \& Gandek, B. (2000). Validation and norming of the MOS 36-item short form health survey in Hong Kong Chinese adults. Health Services Research Committee Dissemination Report no 711026.

7. Sabbah, I., Drouby, N., Sabbah, S., Retel-Rude, N., \& Mercier, M. (2003). Quality of life in rural and urban populations in Lebanon using SF-36 health survey. Health and Quality of Life Outcomes, 1(1), 1.

8. Thumboo, J., Wu, Y., Tai, E.-S., Gandek, B., Lee, J., Ma, S., et al. (2013). Reliability and validity of the English (Singapore) and Chinese (Singapore) versions of the short-form 36 version 2 in a multi-ethnic urban Asian population in Singapore. Quality of Life Research, 22(9), 2501-2508.

9. Cruz, L. N., Fleck, M. P. A., Oliveira, M. R., Camey, S. A., Hoffmann, J. F., Bagattini, A. M., et al. (2013). Health-related quality of life in Brazil: Normative data for the SF-36 in a general population sample in the south of the country. Ciência \& Saúde Coletiva, 18, 1911-1921.

10. Pappa, E., Kontodimopoulos, N., \& Niakas, D. (2005). Validating and norming of the Greek SF-36 health survey. Quality of Life Research, 14(5), 1433-1438.

11. Bullinger, M., Alonso, J., Apolone, G., Leplège, A., Sullivan, M., WoodDauphinee, S., et al. (1998). Translating health status questionnaires and evaluating their quality: The IQOLA project approach. Journal of Clinical Epidemiology, 51(11), 913-923.

12. Blake, C., Codd, M. B., \& O'Meara, Y. M. (2000). The short form 36 (SF-36) health survey: Normative data for the Irish population. Irish Journal of Medical Science, 169(3), 195

13. Apolone, G., \& Mosconi, P. (1998). The Italian SF-36 health survey: Translation, validation and norming. Journal of Clinical Epidemiology, 51(11), 1025-1036.

14. Aaronson, N. K., Muller, M., Cohen, P. D. A., Essink-Bot, M.-L., Fekkes, M. Sanderman, R., et al. (1998). Translation, validation, and norming of the Dutch language version of the SF-36 health survey in community and chronic disease populations. Journal of Clinical Epidemiology, 51(11), 10551068.

15. Scott, K. M., Tobias, M. I., Sarfati, D., \& Haslett, S. J. (1999). SF-36 health survey reliability, validity and norms for new Zealand. Australian and New Zealand Journal of Public Health, 23(4), 401-406.
16. Loge, J. H., \& Kaasa, S. (1998). Short form 36 (SF-36) health survey: Normative data from the general Norwegian population. Scandinavian Journal of Social Medicine, 26(4), 250-258.

17. Eng, B., Wee, H. L., Wu, Y., Tai, E.-S., \& Gandek, B. (2014). Normative data for the Singapore English and Chinese SF-36 version 2 health survey. Annals of the Academy of Medicine, Singapore, 43, 15-23.

18. Jenkinson, C., Coulter, A., \& Wright, L. (1993). Short form 36 (SF36) health survey questionnaire: Normative data for adults of working age. $\mathrm{Bmj}$, 306(6890), 1437-1440

19. Jenkinson, C., Stewart-Brown, S., Petersen, S., \& Paice, C. (1999). Assessment of the SF-36 version 2 in the United Kingdom. Journal of Epidemiology \& Community Health, 53(1), 46-50.

20. Lyons, R. A., Fielder, H., \& Littlepage, B. N. C. (1995). Measuring health status with the SF-36: The need for regional norms. Journal of Public Health, 17(1), 46-50.

21. Demiral, Y., Ergor, G., Unal, B., Semin, S., Akvardar, Y., Kıvırcık, B., et al. (2006). Normative data and discriminative properties of short form 36 (SF-36) in Turkish urban population. BMC Public Health, 6(1), 247.

22. Coons, S. J., Alabdulmohsin, S. A., Draugalis, J. R., \& Hays, R. D. (1998), Reliability of an Arabic version of the RAND-36 health survey and its equivalence to the US-English version. Medical Care, 36(3), 428-432.

23. World Health Organization (1948). Preamble to the Constitution of the World Health Organization as adopted by the International Health Conference, New York, 19-22 June, 1946; signed on 22 July 1946 by the representatives of 61 States (Official Records of the World Health Organization, no. 2, p. 100) and entered into force on 7 April 1948. http:// www.who.int/governance/eb/who_constitution_en.pdf .

24. Guyatt, G. H., Feeny, D. H., \& Patrick, D. L. (1993). Measuring health-related quality of life. Annals of Internal Medicine, 118(8), 622-629.

25. Maruish, M. E. (Ed.) (2011). User's manual for the SF-36v2 health survey, (3rd ed., ). Lincoln: QualityMetric Inc

26. Ware Jr., J. E., Snow, K. K., Kosinski, M., \& Gandek, B. (1993). SF-36 health survey. Manual and Interpretation Guide. Boston: The Health Institute, New England Medical Center.

27. Ware Jr., J. E., Kosinski, M., Bayliss, M. S., McHorney, C. A., Rogers, W. H., \& Raczek, A. (1995). Comparison of methods for the scoring and statistical analysis of SF-36 health profile and summary measures: Summary of results from the medical outcomes study. Medical Care, 33(4 Suppl), AS264.

28. Wild, D., Grove, A., Martin, M., Eremenco, S., McElroy, S., Verjee-Lorenz, A., et al. (2005). Principles of good practice for the translation and cultural adaptation process for patient-reported outcomes (PRO) measures: Report of the ISPOR task force for translation and cultural adaptation. Value in health : the journal of the International Society for Pharmacoeconomics and Outcomes Research. https://doi.org/10.1111/j.1524-4733.2005.04054.x.

29. McHorney, C. A., Jr, W., John, E., Lu, J. R., \& Sherbourne, C. D. (1994). The MOS 36-item Short-Form Health Survey (SF-36): III. Tests of data quality, scaling assumptions, and reliability across diverse patient groups. Medical Care, 32(1), 40-66

30. Howard, K. I., \& Forehand, G. A. (1962). A method for correcting item-total correlations for the effect of relevant item inclusion. Educational and Psychological Measurement. https://doi.org/10.1177/001316446202200407.

31. Ware Jr., J. E., Kosinski, M., Gandek, B., Aaronson, N. K., Apolone, G., Bech, P. et al. (1998). The factor structure of the SF-36 health survey in 10 countries: Results from the IQOLA project. Journal of Clinical Epidemiology, 51(11), 1159-1165.

32. Suzukamo, Y., Fukuhara, S., Green, J., Kosinski, M., Gandek, B., \& Ware, J. E. (2011). Validation testing of a three-component model of short Form-36 scores. Journal of Clinical Epidemiology. https://doi.org/10.1016/j.jclinepi.2010. 04.017.

33. Ware Jr., J. E., Kosinski, M., \& Keller, S. D. (1994). SF-36 physical and mental health summary scales - A user's manual. Boston: The Health Institute.

34. Zumbo, B. D. (1999). A handbook on the theory and methods of differential item functioning (DIF): Logistic regression modeling as a unitary framework for binary and Likert-type (ordinal) item scores. Ottawa: Directorate of Human Resources Research and Evaluation, Department of National Defense.

35. Rose, M., Bjorner, J. B., Gandek, B., Bruce, B., Fries, J. F., \& Ware Jr., J. E. (2014). The PROMIS physical function item bank was calibrated to a standardized metric and shown to improve measurement efficiency. Journal of Clinical Epidemiology. https://doi.org/10.1016/j.jclinepi.2013.10.024.

36. Nagelkerke, N. J. D. (1991). A note on a general definition of the coefficient of determination. Biometrika, 78, 691-692. 
37. Jodoin, M. G., \& Gierl, M. J. (2001). Evaluating type I error and power rates using an effect size measure with the logistic regression procedure for DIF detection. Applied Measurement in Education, 14(4), 329-349.

38. Muraki, E. (1997). A generalized partial credit model. In W. van der Linden, \& R. Hambleton (Eds.), Handbook of modern item response theory, (pp. 153164). Berlin: Springer.

39. Orlando, M., Sherbourne, C. D., \& Thissen, D. (2000). Summed-score linking using item response theory: Application to depression measurement. Psychological Assessment, 12(3), 354-359.

40. Bjorner, J. B., Wallenstein, G. V., Martin, M. C., Lin, P., Blaisdell-Gross, B., Tak, P. C., et al. (2007). Interpreting score differences in the SF-36 vitality scale: Using clinical conditions and functional outcomes to define the minimally important difference. Current Medical Research and Opinion, 23(4), 731-739.

41. McHorney, C. A., Kosinski, M., \& Ware Jr., J. E. (1994). Comparisons of the costs and quality of norms for the SF-36 health survey collected by mail versus telephone interview: results from a national survey. Medical Care, 32(6), 551-567.

42. Charara, R., Forouzanfar, M., Naghavi, M., Moradi-Lakeh, M., Afshin, A., Vos, T., et al. (2017). The burden of mental disorders in the eastern Mediterranean region, 1990-2013. PLoS One, 12(1), e0169575.

43. Lorem, G. F., Schirmer, H., Wang, C. E. A., \& Emaus, N. (2017). Ageing and mental health: Changes in self-reported health due to physical illness and mental health status with consecutive cross-sectional analyses. BMJ Open, 7(1), e013629.

\section{Publisher's Note}

Springer Nature remains neutral with regard to jurisdictional claims in published maps and institutional affiliations.

\section{Submit your manuscript to a SpringerOpen ${ }^{\circ}$ journal and benefit from:}

- Convenient online submission

- Rigorous peer review

- Open access: articles freely available online

- High visibility within the field

- Retaining the copyright to your article

Submit your next manuscript at $\boldsymbol{\nabla}$ springeropen.com 